\title{
IMPLEMENTATION OF INSTRUCTIONAL VIDEOS IN AN ONLINE HEALTHCARE RESEARCH METHODS COURSE
}

\author{
Danielle Henderson, Grand Canyon University
}

\begin{abstract}
A research methods and statistics course is a crucial component of any health care professions program. Statistics is a difficult subject for students to learn, but studies have shown implementing short video lectures in the online platform can enhance student learning and improve course success rates. The purpose of this paper is to detail the implementation of weekly instructional videos in HLT-540, a course with high withdrawal and fail rates, and discuss the impact this had on course success. Short instructional videos were developed and implemented in weeks 2-8 of the 8-week course to provide students with a live demonstration of best strategies for completing assignments, conducting data analysis, and interpreting results. Following the implementation of the instructional videos, $90.5 \%$ of students who completed the course between January and March of 2019, passed. In addition, in end-of-course surveys, students commented on the value of the instructional videos. The $90.5 \%$ course success rate and EOCS feedback supports the continuation of the use of instructional videos in HLT-540 to support student mastery of course objectives. It is important to continue to explore why course success rates increased, so the information can be shared amongst faculty.
\end{abstract}

Keywords: research methods, statistics, online instruction, instructional video, healthcare

\section{INTRODUCTION}

A research methods and statistics course is a crucial component of any health care professions program. Healthcare Research Methods, Analysis, and Utilization (HLT-540) is a required course within healthcare professions graduate programs at Grand Canyon University (GCU). In this course, students learn to assess research studies and research quality, use descriptive and inferential statistics to analyze data in Microsoft Excel, assess statistical significance, and interpret results. This is important in healthcare professions fields, as data is used in the process of designing, implementing and evaluating programs and disseminating findings.

Studies have shown that students struggle to learn statistics, and it may be one of the most rigorous courses students take as a part of their program (DeVaney, 2010). The use of video lectures in the online setting can positively improve student learning (Ozan \& Ozarslan, 2016). Breneiser, Rodefer, and Tost (2018) found that performance in an online psychology statistics course improved after implementing a video series. In the series, which consisted of 28 videos ranging from approximately 3-10 minutes in length, students were provided tutorials for all homework assignments involving the use of SPSS (Breneiser et al., 2018). This length of time is appropriate as students are more likely to completely watch a short video compared to a longer one (Ozan \& Ozarslan, 2016). Through the implementation of the video series, Breneiser et al. (2018) found that student learning was enhanced, and course success rates were similar to a face-toface statistics course. 
In 2018, HLT-540 had a high course withdrawal and fail rate. An online full-time faculty (OFTF) member was hired in October of 2018 to specifically improve success rates of this course. The purpose of this paper is to detail the implementation of weekly instructional videos by the OFTF, and the impact this had on course success.

\section{METHODS}

Instructional videos made by the OFTF via the Google Chrome Extension "Loom," were implemented in the 8-week course, with a goal of providing students with a live demonstration of best strategies for completing assignments, conducting data analysis, and interpreting results. The instructional videos were initially created weekly during the OFTF's first section of the course, which required time and dedication. The instructional videos were then utilized in every section thereafter, with some being re-created and/ or edited and adapted if needed. Students were not able to view the OFTF in the instructional videos, only assignment instructions, assignment resources, GGU resources, or Microsoft Excel. Starting in the second week of the course, on the first day of every week in the Discussion Question (DQ) Forum, students were provided with 1-3 instructional videos embedded in the Learning Management System (LMS) that were less than 6 minutes in length. No instructional video was provided in week 1 , as students were not required to complete an assignment. Throughout the course, 12 total instructional videos were provided. Table 1 gives an overview of each week of the course including the topic title, instructional video objectives and instructional video length.

In weeks 2-4 of the course, instructional videos explained paper-based research assignments. The purpose of the instructional videos was to walk students through the assignment instructions and provided resources (worksheets), which were visible on the OFTF's screen. In addition, students were also instructed on how to access empirical research articles in the GCU library. In the

Table 1. Instructional Video Objectives and Length by Topic

\begin{tabular}{|c|c|c|c|}
\hline Week & Topic Title & Instructional Video Objectives & $\begin{array}{l}\text { Video } \\
\text { Length }\end{array}$ \\
\hline 2 & $\begin{array}{l}\text { Assessing the Quality of Research: } \\
\text { Components and Considerations (Part } 1 \text { ) }\end{array}$ & $\begin{array}{l}\text { Video 1: Provide overview of Evidence-Based Research Interview assignment } \\
\text { instructions }\end{array}$ & 1:18 \\
\hline 3 & $\begin{array}{l}\text { Assessing the Quality of Research: } \\
\text { Components and Considerations (Part 2) }\end{array}$ & $\begin{array}{l}\text { Video 1: Provide overview of Assessing a Research Study assignment instructions, } \\
\text { provide overview of assignment resource } \\
\text { Video 2: Provide overview of Coyne and Messina Articles-Part } 1 \text { Analysis } \\
\text { assignment instructions, demonstrate how to find an empirical research article in } \\
\text { the GCU library }\end{array}$ & 2:01 \\
\hline 4 & Statistics: What You Need to Know & $\begin{array}{l}\text { Vide } 0 \text { : Provide overview of Coyne and Messina Articles-Part } 2 \text { assignment } \\
\text { instructions, describe how to determine what statistical test to use to answer a } \\
\text { research question, explain assignment resource }\end{array}$ & 5:04 \\
\hline 5 & $\begin{array}{l}\text { Fundamentals of Samples and Nominal and } \\
\text { Ordinal Statistics }\end{array}$ & $\begin{array}{l}\text { Video 1: Provide overview of Broyles Textbook Practice Exercise assignment } \\
\text { instructions, demonstrate how to use the data analysis feature in Microsoft Excel } \\
\text { to conduct descriptive statistics }\end{array}$ & $3: 07$ \\
\hline 6 & Interval and Ratio Statistics (Part 1) & $\begin{array}{l}\text { Video 1: Demonstrate how to use Microsoft Excel to conduct a Pearson correlation } \\
\text { Video 2: Demonstrate how to conduct a t-test in Microsoft Excel }\end{array}$ & $\begin{array}{l}2: 49 \\
3: 01\end{array}$ \\
\hline 7 & $\begin{array}{l}\text { Interval and Ratio Statistics (Part 2) and the } \\
\text { Concept of Significance }\end{array}$ & $\begin{array}{l}\text { Video 1: Provide overview of Yeung Analysis assignment instructions, provide } \\
\text { overview of resource } \\
\text { Vide } 0 \text { 2: Demonstrate how to conduct an ANOVA in Microsoft Excel and interpret } \\
\text { the results } \\
\text { Video 3: Demonstrate how to conduct a regression analysis in Microsoft Excel and } \\
\text { interpret the results }\end{array}$ & $\begin{array}{l}1: 54 \\
2: 33 \\
4: 22\end{array}$ \\
\hline 8 & Using Research in a Health Care Setting & $\begin{array}{l}\text { Video 1: Provide overview of Stakeholder Scenario assignment instructions } \\
\text { Video 2: Provide overview of Proposal Development Paper assignment instructions }\end{array}$ & $\begin{array}{l}2: 07 \\
2: 34\end{array}$ \\
\hline
\end{tabular}


instructional videos for weeks 5-8, video objectives centered around data analysis and interpretation. Assignment instructions were clarified, and students were able to view a demonstration of how to conduct the analysis in Microsoft Excel and interpret the results.

To evaluate success of the implementation of instructional videos course success rates and qualitative feedback from students' end-of-course surveys (EOCS) were examined.

\section{RESULTS}

Seventy-four students were enrolled in sections of HLT-540 taught by the OFTF ending between January and March of 2019 (Quarter 1). In Quarter $1,90.5 \%$ of students successfully completed the course, $2.7 \%$ of student failed the course, and $6.8 \%$ of students withdrew from the course. Table 2 Provides examples of the qualitative feedback that was received by students on EOCS from January through June of 2019 (Quarter 1 and Quarter 2). Students stated the instructional videos clarified assignments, helped with assignments, and increased their understanding of assignments.

\section{DISCUSSION}

The goal of incorporating instructional videos was to provide students additional resources to meet course objectives, similar to what they would have received in a face-to-face environment. Over $90 \%$ of students passed when instructional videos were used by the OFTF in HLT-540. In addition, students commented on the value of instructional videos in EOCS. These findings are in alignment with previous studies that show implementation of instructional videos in a statistics course can improve the percent of students who remain in the course and complete the course with a passing grade (Breneiser et al., 2018).

To continue to improve course success rates, the OFTF believes the instructional videos can be enhanced through collaboration with additional subject matter experts. Having faculty input on instructional videos will ensure videos are in alignment with course objectives (Breneiser et al., 2018).

One limitation of these findings is that prior to the OFTFs hiring, sections of the course were taught by several adjunct faculty, while currently the OFTF teaches all sections of the course. The OFTF is unaware if any instructional videos were utilized by adjunct faculty. Therefore, it is difficult to determine if the use of instructional videos alone can explain the success rate, or if having one faculty member assigned to the course improves outcomes.

It is often that students enter HLT-540 unsure of the role statistics has in healthcare professions. Through completing the course, students gain a

Table 2. Qualitative Feedback Received on 2019 EOCS by Month

\begin{tabular}{|c|l|}
\hline Month and Year & \multicolumn{1}{|c|}{ Examples of Qualitative Feedback } \\
\hline January & $\begin{array}{l}\text { Adds additional videos and instructions to clarify assignments. } \\
\text { Instructor was very involved and provided videos to help with assignments } \\
\text { She did additional videos helping with assignments }\end{array}$ \\
\hline February & $\begin{array}{l}\text { [Instructor] took the time to record and post instructional videos on assignments, posted assignments discussion in forum. } \\
\text { Made it easier to understand the material and complete challenging assignments } \\
\text { Excellent communication with the video she provide to understand the assignments. I have never had that in my other GCU } \\
\text { classes and this was a big help. } \\
\text { Iloved how the professor created tutorial videos. These were especially helpful with the Excel assignments. }\end{array}$ \\
\hline April & $\begin{array}{l}\text { She also took the time to thoroughly explain assignments. } \\
\text { She was very helpful and provided videos explaining assignments. }\end{array}$ \\
\hline May & $\begin{array}{l}\text { Available for questions and very thorough with assignment instructions } \\
\text { Iloved the videos that she provided and the lecture notes too. }\end{array}$ \\
\hline June & $\begin{array}{l}\text { Ilike that she gave videos with each assignment, it made me feel as if I were in a classroom. } \\
\text { [Instructor] ensures that her students understands the topic as well as the assignments by using tutorial videos. } \\
\text { [Instructor] goes above and beyond to ensure her students are understanding the components of the course by providing } \\
\text { videos and examples of assignments. }\end{array}$ \\
\hline
\end{tabular}


deeper understanding of how statistics are used in every field within healthcare. The $90.5 \%$ course success rate and EOCS feedback supports the continuation of the use of instructional videos in HLT-540 to improve student mastery of course objectives. It is important to continue to explore why course success rates increased, so the information can be shared amongst faculty.

\section{References}

Breneiser, J., Rodefer, J., \& Tost, J. (2018). Using tutorial videos to enhance the learning of statistics in an online undergraduate psychology course. North American Journal of Psychology, 20(3), 715-729.

DeVaney, T. A. (2010). Anxiety and attitude of graduate students in on-campus vs. online statistics courses. Journal of Statistics Education, 18(1), 1-15. doi:10.1080/10691898.2010.11889472

Ozan, O., \& Ozarslan, Y. (2016). Video lecture watching behaviors of learners in online courses. Educational Media International, 53(1), 27-41. doi:10.1080/09523987.2016.1189 255 